\title{
Communication and Sport A Call to Action
}

https://doi.org/10.21814/uminho.ed.46.18

\section{Paulo Salgado}

Communication and Society Research Centre, Institute of Social Sciences, University of Minho, Braga, Portugal

https://orcid.org/0000-0001-5503-4134 



\begin{abstract}
The economic influence of media has dramatically changed the world of sport, leading sports organisations to increase their focus on communication and assets like brands and reputation. The intent for a more strategic communication within the sports industry must consider a broader and more profound reflection of how the world of sports intertwines with communication and its interactive process of creation, selection, and retention of meaning (Weick, 1979). As a practice and as a business, the social role played by sports, and the singularities of sports organisations are central pieces for the comprehension of the strategic sports communication model presented in this paper. It aims at encouraging researchers to dive into the realm of sports communication.
\end{abstract}

\title{
Keywords
}

sports communication, strategic communication, organisational communication

\section{Introduction}

"Talking about sport scientifically is difficult because in one sense it is too easy: everyone has their own ideas on the subject and feels able to say something intelligent about it" (Bourdieu et al., 1998, p. 15).

Sports and communication do matter. The economic influence of media has created dramatic changes in sports, promoting changes in how we relate to it. These transformations have affected the stories told through sport, in service of industry, of a brand or an organisation with commercial intents (Wenner, 2013). Whether it is controversial or not to call it an industry (Gammelsæter, 2020), sport-oriented businesses increased their focus on their communication efforts to manage brands, sponsor events and use brand-building and image transfer as justifications for their investments (Gladden, 2013). Despite that, strategic sport communication can comprise more than that. Pedersen (2013) suggests a holistic communicational approach:

all components-activity, organisation, or individual involved in the sport management and marketing-are affected by communication. Thus, from an economic and strategic point of view, communication and sport matter because they work together to form an influential and pervasive relationship throughout societies and economies. Simply stated, sport cannot exist without communication. (p. 57) 
Wenner (2013), in his essay, dives deeper into this intertwined relationship between sport and communication and answers why communication is so significant in the world of sport: (a) communication offers us a frame through which we comprehend and share our cultural understandings about sport and its place in society; (b) communication about sport gives a language frame of how we think about politics; (c) sports communication also matters because it has the potential to influence our identities. The author also gives the example of gender as a great divide in sport: (d) sport is a kingpin of media consumer cultures, as it is a form of reaching large audiences - the Football World Cup, the most prominent football competition on the planet, has a cumulative global audience reach of over $3,500,000,000,000$ spectators according to the Fédération Internationale de Football Association (Fifa) official numbers; and (e) the influence of media in the way stories are told through sport, influencing people and organisations in the service of an economic or marketing endeavour.

This work aims to promote a call to action to the research in communication and sports by providing a deeper reflection on how world sport intertwines with communication and its interactive process of creating meaning and how it affects the strategic communication intents. It seeks to increase researchers' motivation to look at sport organisations singularities where communication plays a pivotal role. As stated by Wolfe et al. (2005), "the use of sport in organisational studies knows no boundaries" (p. 184) and that it can bring joy, interest, amusement, fascination to the researcher's work. According to Wolfe et al. (2005), research on sport can widen the range of attention, cognition, and action to the entire area of research.

\section{Sport and Communication as Symbolic Processes}

The analysis of communication as the central force of organising, summarised in the famous perspective of the communicative constitution of organisations, which highlights the effect of language and discourse in the construction of meaning and social coordination, is an increasingly transversal topic in organisational communication research. In 1979, Karl Weick proposed that communication builds organisations through symbolic processes of creation, selection, and retention of meanings. Christensen and Cornelissen (2013) also highlight this topic, as Taylor and Every (2014) give examples of how research in organisational communication focuses, in an ever more profound way, on topics such as internal change and the identity processes that confer an interdisciplinary and distinctive theoretical 
body. Wolfe et al. (2005) also refer to the importance of identity-related research topics for organisational sport studies. That can be related to how an individual maintains an affiliation with a team or organisation that fails or "when individuals find the identity of the organisation (or sports team) to be attractive, they use their association with the entity to define themselves" (Wolfe et al., 2005, p. 203).

Weick (1979) argued that human beings are reconstructing reality through mechanisms of attribution of meaning that rationalise the significance of their actions and, based on this, argued that communication is central to human life and organisations because it is the central process of organising. Moreover, like organisations, sport cannot exist without communication (Pedersen et al., 2007), in such a way that communication plays a central role in sport, whether we speak about symbolic and sense-making processes, whether we look at a strategic or economic point of view, as the sports industry thrives as a worldwide phenomenon (Gladden, 2013). Pedersen et al. (2007) propose a definition of sport communication as "a process by which people in sport, in a sport setting, or through a sport endeavour, share symbols as they create meaning through interaction" (p. 196).

Communication and sports seem to walk intertwined, to further research might contribute to a deeper understanding of our society (Pedersen, 2013; Wenner, 2013). Fredrickson (2003) even considers that research focused on sports institutions can contribute to a new look at certain phenomena of reality. Thus, one may believe that this perspective can and ought to be equally valid for the study of communication in sports organisations. Despite these points of view, Bourdieu et al. (1998) warn of the difficulties in developing the sociology of sport. The odd trait requires the researcher to be remarkably proficient in two different worlds: Sociology and sport.

Furthermore, Bourdieu et al. (1998) go further in their consideration, stating: (a) that some know the world of sport very well, but do not know how to talk about it; (b) that there are those who, not knowing the world of sport deeply, could talk about it, but disdain doing so; and (c) others who do so without adequate ownership. In 1991, the assessment made in the Annual Review of Sociology highlighted the lack of theory development around this field.

For Costa (2010), sport can also be seen as a mirror of society or even be a social phenomenon with planetary dimensions, symbolic nature and ritual functioning, which makes it capable of representing the most varied aspects of a global society. That is a topic that Wolfe et al. (2005) identify as a 
recurring theme in terms of sports research - a microcosm of broader society. For the authors, sport is an institution that provides scientific observers with a convenient laboratory to examine values, socialisation, stratification, and bureaucracy, naming just a few of the structures and processes identified at this societal level.

Keidell (1987) goes further in the relationships with social spaces, such as organisations:

the world of sport mirrors the world of work; the structures of the game are parallel to the structures of work. All three major sports, football, basketball and baseball, generically represent an organisational model. Baseball is a metaphor for the autonomy of the organisational parties, football is about the hierarchical control of the parties, and basketball is about voluntary cooperation between the parties. (pp. 591-592)

Eitzen and Sage (1997) also verified the notion of being in front of a microcosm in the social space. The authors affirm that the types of games people choose to play; the degree of existing competitiveness; the sort of rules; the constraints faced by athletes and the sports themselves; the pace and variety of changes promoted; and the reward system in sport provide a microcosm of society, a mirror that portrays a broader reality. Still, it is worth noting that this vision of a microcosm that can offer relevant data for a better understanding of society, organisations and the communication activities related to sports activities does not necessarily imply seeing sport or any sports practice as a universe by itself.

Bourdieu (1988) is clear about adopting a vision of sport included in a whole universe of practices and consumption that form a system with which the sports universe is related. Even if it is legitimate to consider sport as a universe with its legitimacy, the researcher must pursue a more precise analysis to define the entire space under consideration. We are facing two similar spaces, a space of practices - the offer; and a space for provisions for practice - demand. This dialectic between (a) a space characterised by its technical and intrinsic properties, and defined considering all other structures and properties of other sports spaces also offered at a given time; and (b) another space characterised by the dominant dispositions which determine the possible uses and can be portrayed at every moment by the dominant use of them. The relationship between the intrinsic truth of sport and its social truth encompasses the main interpretations of it. 
One can see this perspective through the philosophical and symbolic dimensions related to sports practice in football. For Bourdieu (1988), just as a philosophical work, reinterpreted from generation to generation, sports practices may be constantly reinterpreted and generate different meanings. In the same way, communication practices within an organisation may be reinterpreted, in the form of a zeitgeist, in a world constantly changing and adapting to new forms of communication and media. Specific ways of looking, seeing and practising the sport marked an era the same way technological advances, such as the internet and social media online platforms, marked an era changing how we relate to one another. The Netherlands team became an icon of the 1970s through the practice of what became known as "total football", guided by Rinus Michels and based on the irreverence and genius of Johan Cruijff. Although the Clockwork Orange ${ }^{1}$ (as the Dutch team of the decade is also known) has won nothing, its style represents a typically Dutch concern with the overall systems and notion of space, which is part of its painting and architecture. For Winner (2008), "total football" was deeply imbued with democratic impulses, a perfect balance between collective responsibility, equality, and individualism - a system in which each player is allowed to surpass himself and express himself. The reverse side of the medal is a system in which discipline and cohesion are always fragile. The author adds, South American football, unlike the Dutch, attaches less importance to the system and more importance to the human being who is the centre of his football. Winner (2008) also compares the Italian catenaccio (a system that created roots in Italian football for decades and based on a defensive system consisting of a free-and-clear defender and four defenders) to a picture of the Italian artist Ticiano - soft, seductive, and languid who accepts and embraces the opponent, to later betray him, through a goal on the counterattack, scored with the speed of a dagger.

According to Bourdieu (1988), a sport becoming more relevant in society has two different meanings: (a) it describes an objective program of sporting practices, using terms such as "football", "tennis", or "swimming", and confronts athletes; or (b) as a way of describing the right or suitable form of exercising the program, that is, the modality itself. Sport as a social construction takes on different perspectives and meanings throughout its evolution and its physical and temporal space in society. According to the dominant practices, use and various modalities, the interpretations of sport

\footnotetext{
${ }^{1}$ Winner (2008) describes the style of football played by the Netherlands as "clockwork orange" - because the team usually wears orange jerseys and a clockwork because the individual members of the team play with the mechanical perfection of the world's best timepieces.
} 
generate transformations in terms of practices affecting its meaning, practice, and place in each culture. These constant changes, referring to Wolfe et al. (2005), let us look at sport as a laboratory for social research.

\section{Sport Organisational Singularities and Assets}

The management of sports organisations in the 21st century involves applying techniques and strategies common to most companies, governments or non-profit organisations. Sports managers must be involved in strategic planning and manage a multitude of human resources such as: television broadcasting contracts that can be worth millions of euros; the well-being and mood of their top athletes, whose salaries are 100 times that of a medical career; a whole network of internal and external relationships, from the media, communities, other clubs, national and international federations, governments, sponsors, government institutions, among others (Hoye et al., 2015).

According to Stewart and Smith (1999), the sport has specific characteristics requiring sports management to apply appropriate management techniques. One of its most distinctive attributes is that people develop an irrational passion for teams, competitions, and athletes. Sport does have a symbolic dimension, a meaning concerning performance, success, the celebration of achievements, which does not exist in other social and economic areas. There are differences between sports organisations and other types of organisations and how they assess performance. Whether private or public, companies exist to make profits, to increase the wealth of their shareholders and investors, while in sport, there are other priorities or imperatives, such as winning titles, championships, providing community support that overrides financial results. Managing sports organisations involves striking a balance between the multiple performance outcomes expected for the organisation and its economic sustainability.

Sports organisations compete with one another on the field of play, although off of it, they are often bound to cooperate to ensure the clubs', leagues', and competitions' survival. That is also one of the singularities of sports organisations compared to business markets where competitors are not forced to work together. In most business areas, the aim is to secure the largest possible market share, outperforming the organisation's competitors and securing a monopoly. On the contrary, in sport, clubs need each other to keep competing. Moreover, in many cases, this cooperation 
even makes teams share profits, manage the uncertainty of matches, and showcase their top talents to ensure their fans or supporters' continued support and interest. This environment can even be considered uncompetitive. Loaning players to other clubs, which they will have to play against, has, for example, been the subject of constant controversy in football, even requiring constant attention to regulations (Smith \& Stewart, 2014).

When it takes a form of a game or challenge, the sports product also varies in quality. The outcomes of matches are usually uncertain, but if only one team or one player becomes dominant, the interest and attractiveness of the game or sport itself tend to decline. For this reason, it is harder to guarantee the quality of the sports product compared to a product any consumer can buy, as the quality tends to be similar if the purchased product is the same. It is essential to manage perceptions without compromising quality. In motor sport, if one team or one driver becomes dominant, it is common to change the rules to keep the sport competitive

Sports brands, for instance, have become ubiquitous in the business of sport. "The last 20 years have seen sport-oriented businesses increase their focus on managing brands to increase brand equity. Increasingly, corporations sponsoring sport and events use brand-building and image transfer as justifications for their financial investments" (Gladden 2013, p. 3). This critical asset for businesses depends not only on the different roles and functions based on supply and demand but also on the financial value that brands now account for in sports organisations (Nufer et al., 2017). According to Bridgewater (2010), the brand has become increasingly important in sports organisations such as football clubs, implying a need for a more acrossthe-board and systematic approach to brand management. Nonetheless, Nufer et al. (2017) also point out that the principles for brand identity management rarely apply within Bundesliga clubs, despite the high economic potential and the possibility to provide a competitive financial advantage.

Sport and, particularly, clubs enjoy high loyalty to their brand. The likelihood of a fan changing clubs due to a bad game or even one or more bad seasons is low. In contrast, a consumer of other types of products generally has a wide range of brands and products to choose from, and these can quickly make the consumer change opinions depending on price or quality. Though, if on the one hand, we are before the advantage of the sports product, on the other, we can also admit that the ability to attract new fans or to win them over a rival club is much less (Bridgewater, 2010). 
Another asset that can be considered key for a sports organisation is its reputation and relationship with its stakeholders. Sports organisations are, by default, corporate brands, which entails a broader engagement with different vital stakeholders. That does not happen for product brands more focused on product and customer relationship management. To Bridgewater (2010), a corporate brand name is more likely to suggest mental associations related to products, experiences, shared values, attributes, and benefits, people and relationships, and corporate credibility. All these associations can connect to an effect on brand equity and performance of single products. To Argenti and Druckenmiller (2004), "a company engages in corporate branding when it markets the company itself as a brand" (p. 368). That is the case of sports clubs, where the brand name, logo, and team stand for all. The goods and services offered are seen as a part of the company's identity. For Keller (2013), a solid corporate brand is firmly attached to the company's need to maintain a high public profile to influence and shape some of the mental representations held by the different stakeholders, hence reputation.

Argenti and Druckenmiller (2004) define corporate reputation as "the collective representation of multiple constituencies' images of a company, built up over time and based on a company's identity programs, its performance and how constituencies have perceived its behaviour" (p. 369). According to Salgado and Ruão (2013), if one applies this perspective to the sports industry, a good corporate reputation will provide benefits: (a) at the top, football clubs struggle to allure best sponsors and investors; (b) in attracting the best players, coaches and managers for their squads (applicants); (c) in increasing stadium attendances; (d) in maintaining supporters, fans and customers satisfied; (e) in creating value for the brand and products and therefore increase sales; (f) for the perceived value of the teams' football players and consequently obtain higher bids from other clubs, in the player's transfer market.

Sport can evoke unique behaviours in people, such as copying their heroes in the game, wearing the kit or jersey of their favourite club or player, and buying products that celebrities or idols advertise. Sports management can use the fact that supporters identify with the skills, abilities or lifestyle of sports personalities to create partnerships that influence their key audiences.

The fans are generally more optimistic in the face of a bad scenario, such as a series of defeats, invoking reasons such as luck being decisive to achieve a good result. (Aichner, 2019; Bridgewater, 2010; McCarthy et al., 2014; Smith \& Stewart, 2014). Stewart and Smith (1999) and Smith and Stewart 
(2014) also argue that sports organisations are more reluctant to adopt new technologies unless related to sports science leading to some performance advantage. In this sense, many sports organisations tend to be somewhat conservative, more attached to traditions and behaviour than other types of organisations. If we consider, for example, today's widespread use of social media platforms that, according to Aichner (2019), adds value: (a) in providing services to consumers; (b) as a marketing channel to advertise products and increase brand awareness; (c) consequently leading to better brand loyalty - considering professional football clubs use social media strategically, which according to the author is not certain.

Nevertheless, McCarthy et al. (2014) and Aichner (2019) point out that even if there is a considerable amount of research on the strategic and operational use of social media platforms when it comes to a systematic review of why and how football clubs use social media and engage on these platforms strategically nothing comes up. The lack of knowledge and research available to marketing and communication managers on to what extent sports clubs use social media in their marketing and communication strategy is quite significant as it would: (a) provide an assessment on the importance football clubs give to some social media platforms, compared to others; (b) offer a benchmark about the competitors' performance; (c) provide a deeper assessment of the return-on-investment; (d) produce more information for human capital and budget management, boosting organisational performance and efficiency. Despite this scenario, the mass use of social media platforms is now a reality for sports organisations worldwide.

Finally, another aspect that sets sports organisations apart from other types of organisations is their limited availability. In sports, clubs are limited by seasons with a defined number of matches per year. In other industries, companies can quite easily increase production to meet demand.

\section{The Professionalisation of Sport: The Birth of a Business}

One can describe sports as activities requiring physical exercise, structured and standardised under internationally defined regulatory rules. In this sense, it is relevant to make a clear distinction between organised sports (competition) and sports as non-competitive and recreational leisure activities. This boundary between organised and unorganised sport identifies two existing markets in which sports organisations seek to develop their business. While many sports organisations do not aim to generate profits 
for their investors and shareholders, they generally seek out a financial outcome to promote and professionalise the sport itself. Thus, according to Spaaij and Westerbeek (2010), it makes sense to establish a difference between sports organisations that seek profit and others that seek to generate a surplus. According to the authors, the latter tend to create profit to obtain funds to finance their presence in sports competitions. In the football industry, sports organisations (or companies) seek to generate the most diverse types of income to fund their teams, hire new players, and pay high salaries to athletes and coaches. The aim is to attain the sought-after success, which supersedes the institutions' targeted sustainability and financial growth. Organisations that use sport as part of their communication strategy or are active sponsors are not considered sports business organisations in this sense.

Wherever one plays it, professional sport is the most viewed sport, the most expensive and attracts the most attention. It has a tremendous capacity to generate media coverage, to attract sponsorship and support from large companies (Boyle, 2009). Sport may have been played for a while for pure leisure by amateur athletes, but professional sport and the industry that accompanies it dominate the world of sport and those who play it. Athletes quickly become cultural icons on a global scale. Whether locally, regionally, nationally or internationally, companies that gravitate in this industry now exist for the support they give to sports leagues to develop athletes and spectators' interest. These same organisations must often compete for media coverage, sponsorship and support from fans and communities or government entities. One can observe the same type of phenomena in the rise of eSports. Jenny et al. (2014) also discuss how eSports now fit within the definition of sport and the mediatisation that accompanies this activity and the industry that gravitates around it.

On the other hand, one can even consider that sport, as a business, is insatiable in its appetite for financial, social, and cultural resources. Hoye et al. (2015) point out that professional sport is an appendix of the sports industry that supports sports organisations that need to generate financial resources and cultural capital. Professional football leagues, for example, are so rooted in the identity and culture of social groups that they can even determine what it means to belong to those same groups. According to the authors, professional football leagues and their clubs have become essential for many fans and supporters to understand themselves and define who they are.

Organisations that engage in sport as a business are primarily concerned with maximising their economic capital. In this perspective, Andrews (2004) even 
suggests that these organisations are a symbol, or an emblem, of neoliberal capitalist movements. In turn, it is also relevant to consider the importance of social capital that these organisations promote. Social capital highlights the benefits of meaningful social relationships based on social trust and the generalisation of reciprocity. While critics see the first perspective (maximisation of economic capital) as a promoter of social inequality, the latter (promoting social capital) reduces inequalities and promotes a community spirit and well-being. Spaaij and Westerbeek (2010) advocated that business sports organisations can contribute to more outstanding social capital.

\section{Strategic Communication and Sports}

Strategic communication is a recently established research area within communication sciences that analyses the use of persuasive communication to achieve organisational goals. It is a broad field encompassing different technical areas such as public relations and other corporate communication activities (such as advertising; Araújo \& Ruão, 2014). Hallahan et al. (2007) argue that it is essential to look at an organisation's communication activities from a strategic and integrated viewpoint since this is a practice increasingly exploited by companies/institutions to perform better to achieve their goals. According to Smith (2013), strategic communication is:

intentional communication undertaken by a business or non-profit organisation, sometimes by a less-structured group. It has a purpose and a plan, in which alternatives are considered and decisions are justified. Invariably, strategic communication is based on research and is subject to eventual evaluation. It operates within a particular environment, which involves both the organisation and groups of people who affect it in some way. (p. 5)

For Kitchen (1997), strategic communication incorporates three main components: marketing communication, human resources, and public relations. The integrated vision of Cornelissen (2008), who considers the coordination of all communication media efforts, is underlined by Brønn (2013). For the author, strategic communication is seen holistically as a mindset since its main objective is to manage all the processes that integrate and involve communication as a whole. She highlights that this perspective assumes that strategic communication can incorporate the experience and knowledge of many communication disciplines, including public relations, communication marketing, organisational communication, human resources 
management, to integrate and manage different messages under the same umbrella (Cornelissen, 2008).

Brønn (2013) refers that organisations need to take a long-term approach to build and manage their communication assets like reputation, which involves strategy, marketing, human resources management, and communication. The author even claims that there is already ample evidence that the responsibility for building reputation, from a strategic focus, lies, if not entirely, then substantially, in the role of strategic communication.

If strategic communication tends to be seen as indispensable for creating a distinctive image, creating a solid institutional brand and developing it is a central idea in the organisational reputation literature (Brønn, 2013; Dowling, 1994; van Riel, 1995). For van Riel and Fombrun (2007), the success of the organisation's entire communication system is measured by its reflection on the organisation's reputation.

Pedersen et al. (2007) offer a perspective on strategic communication on sport, a phenomenon recognised as a "dynamic process between institutions, texts, audiences in the public sphere" (p.196). The authors pursue this idea revealing the need of sports organisations, media, fans, agents, media networks, and leagues to communicate to and through each other. Even if the need for profit is a central piece in the industry of sport, different organisations might have different communication goals to achieve:

networks seek high ratings and advertising revenue from sponsors and corporations, leagues, teams, and athletes. Teams and leagues seek high exposure through the media, large gate profits through fans and sport enthusiasts, and rely on the successes of their individual workers for sustenance. (Pedersen et al. 2007, p. 196)

Organisations try, through networks, to gain recognition, awareness and add value to their products and programs. As for the fans, they can receive or reject the content given, as they can watch, listen, influence, read or buy and consequently influence rating, awareness, and exert power. This perspective reinforces the importance of the strategic communication process to consider the context and all the stakeholders involved with the organisation. As Cornelissen (2004) states, "the central concern of strategy is with matching or aligning the organization's mission, and its resources and capabilities, with the opportunities and challenges in the environment" (p. 98). Figure 1 below is an adaptation of the analysis 
from A.T. Kearney (Collignon \& Sultan, 2014). It represents the money flow where media companies, brands, sports leagues, clubs, cities, and countries struggle and work together to grow and to obtain more revenue in the sports event market (in 2017 valued at $\$ 90,900,000,000,000$ ) and where a strategic communication approach is required.

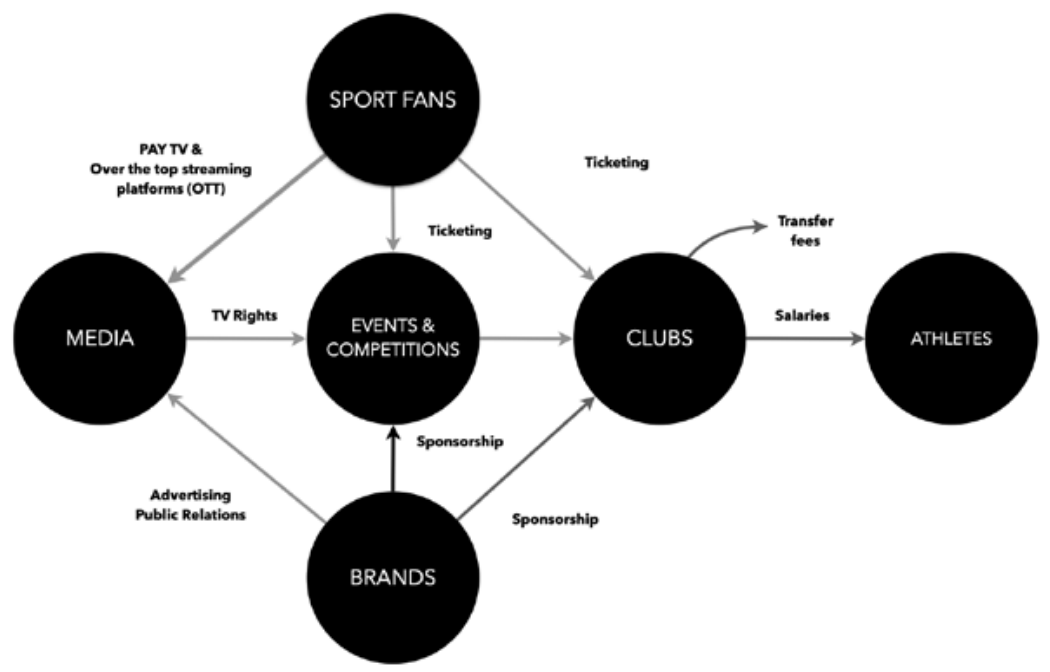

Figure 1 The sports ecosystem flow of money

Note. Adapted from Collignon \& Sultan, 2014

Pedersen et al. (2007) consider three types of communication within communication in sports: (a) the communication in sports, related to the communication within the field of play; (b) communication in a sport setting that comprises all the communication within the sports organisations; and (c) the communication through sport, such as advertising or sponsorship that occur through a means of a competition, or a sporting event. In 2012, Pedersen proposed a strategic sport communication model (Table 1), presenting three interrelated strategic components to be considered in the development of a communication strategy for sports organisation: (a) personal and organisational communication in sport; (b) sports mass media (and social media as well); (c) ancillary sport communication (which include activities like public relations, advertising, media relations, community management). 
Table 1 Sport strategic communication model components.

Source. Pedersen, 2012

\section{Personal and organization communication aspects \\ Intrapersonal, interpersonal, and small-group communication in sport; intraorganizational and interorganizational communica- tion in sport}

Examples of topics in research

Corporate social responsibility practices; organisational culture; jobs satisfaction; sexual harassment; coverage trends; verbal communication, nonverbal communication
Sports mass media aspects

Traditional media (e.g., newspapers, radio, television, publishing, movies) to emerging media (e.g., new media, social media)

Examples of topics in research

Television viewership; emerging sport broadcast technologies; print media coverage of athletes; sport radio broadcasts; the portrayal of athletes in magazines; controversial Super Bowl halftime broadcasts
Ancillary sports communication aspects

Sport public relations, advertising in and through sport, media relations, community relations, crisis communication, practical and theoretical research in sport communication, branding, sport management, and marketing

Examples of topics in research

Strategic communication/ public relations activities and campaigns; sport funding campaigns; sponsorship programs

The perspective provided by Pedersen (2012) highlights a holistic approach that we can connect to organisation communication studies and research, and where communication plays a central role in creating meaning and sense-making activities, while it also addresses the use and analysis of media and the strategic purpose of the organisation. When Deetz (2001) analyses the communication phenomena of organisations, he considered the speciality of agency departments, and we can easily relate them to Pedersen's (2012) sports media and its ancillary components. When Deetz (2001) refers to the particular phenomenon occurring in the organisation and describes and explains the organisation, we can associate these two topics with Pedersen's (2012) personal and organisational aspects. The structure presented can be useful to organisational and strategic communication researchers as it helps define their investigation topics within a narrower scope. That might be convenient to understand how particular communication phenomena affect and influence the organisation and the relationship with different stakeholders and audiences. 


\section{A Final Note}

This work intended to demonstrate that sport may benefit the understanding of organisations' management and communication and highlight the fascination that the examples drawn from sport seem to provoke in corporate management professionals. According to Parlebas (1986), the sports game portrays a micro-society, marked by its limits within space, time, and the number of participants and their modes of interaction - even the transformation of sports relates closely to the development of new media forms. There is a relation between the fact that sport is considered a mirror of society and the social phenomenon of planetary dimensions, symbolic in nature and ritual in operation, which gives it the ability to represent all aspects of global society (Costa, 2010). Given this close connection between sport, identities, communication, organisations, communities, and media, it became clear and relevant that any strategic communication program must address the singularities of sports organisations, with constant attention to stakeholder management. That will enhance the creation of value for the brand and promote a positive organisational reputation and a more profound look at all communication processes of creating, selecting, and retaining meaning.

English revision: Anabela Delgado

\section{Acknowledgements}

This work is supported by national funds through FCT - Fundação para a Ciência e a Tecnologia, I.P., under the project UIDB/00736/2020.

\section{References}

Aichner, T. (2019). Football clubs' social media use and user engagement. Marketing Intelligence \& Planning, 37(3), 242-257. https://doi.org/10.1108/MIP-05-2018-0155

Andrews, D. L. (2004). Manchester United: A thematic study. Routledge.

Araújo, R.A.M., \& Ruão, T. (2014).A comunicação estratégica na saúde: A relação de poder entre a assessoria de imprensa e o jornalismo. In T. Ruão, R. Freitas, P. Ribeiro, \& P. Salgado (Eds.), Comunicação organizacional e relações públicas: Horizontes e perspetivas. Relatório de um debate (pp. 100-115). Centro de Estudos de Comunicação e Sociedade. http://www.lasics.uminho.pt/ ojs/index.php/cecs_ebooks/article/view/2006

Argenti, P. A., \& Druckenmiller, B. (2004). Reputation and the corporate brand. Corporate Reputation Review, 6, 368-374. https://doi.org/10.1057/palgrave.crr.1540005 
Bourdieu, P. (1988). Program for a sociology of sport. Sociology of Sport Journal, 5(2), 153-161. https://doi.org/10.1123/ssj.5.2.153

Bourdieu, P., Dauncey, H., \& Hare, G. (1998). The state, economics and sport. Culture, Sport, Society, 1(2), 15-21. https://doi.org/10.1080/14610989808721813

Boyle, R. (2009). Power play: Sport, the media and popular culture. University Press.

Bridgewater, S. (2010). What is a football brand? In S. Bridgewater (Ed.), Football brands (pp. 11-45). Palgrave Macmillan. https://doi.org/10.1057/9780230281363_2

Brønn, P. S. (2013). Corporate reputation and the discipline of corporate communication. In. P. S. Brønn (Ed.), The handbook of communication and corporate reputation (pp. 53-61). Wiley-Blackwell.

Christensen, L. T., \& Cornelissen, J. (2013). Bridging corporate and organizational communication: Review, development and a look to the future. In A. Zerfaß, L. Rademacher, \& S. Wehmeier (Eds.), Organisationskommunikation und Public Relations (pp. 43-72). Springer. https://doi. org/10.1007/978-3-531-18961-1_3

Collignon, H., \& Sultan, N. (2014). Winning in the business of sports. Kearney. https://www.kearney.com/communications-media-technology/article?/a/winning-in-the-business-of-sports

Cornelissen, J. (2004). Corporate communications theory and practice. Sage.

Cornelissen, J. P. (2008). Corporate communication. In W. Donsbach (Ed.), The international encyclopedia of communication (pp. 1-7). International Communication Association (ICA); Wiley-Blackwell.

Costa, A. (2010). A sociologia do desporto e novas perspectivas para a sociologia geral. Exemplo: 0 caso do futebol. In M. L. Martins (Ed.), Caminhos nas ciências sociais (pp. 31-48). Grácio Editor.

Deetz, S. (2001). Conceptual foundations. In F. Jablin \& L. Putnam (Eds.), The new handbook of organisational communication: Advances in theory, research, and methods (pp. 3-46). Sage.

Dowling, G. R. (1994). Corporate reputations: Strategies for developing the corporate brand. Kogan Page.

Eitzen, D. S., \& Sage, G. H. (1997). Sociology of North American sport. Brown \& Benchmark Publishers.

Fredrickson, B. L. (2003). The value of positive emotions: The emerging science of positive psychology is coming to understand why it's good to feel good. American Scientist, 91(4), 330335. https://doi.org/10.1511/2003.4.330

Gammelsæter, H. (2020). Sport is not industry: Bringing sport back to sport management. European Sport Management Quarterly, 21(2), 257-279. https://doi.org/10.1080/16184742.2020.1741013 
Gladden, J. (2013). Brand equity: Management and measurement in sport. In M. Pritchard \& J. Stinson (Eds.), Leveraging brands in sport business (pp. 3-20). Routledge.

Hallahan, K., Holtzhausen, D., van Ruler, B., Verčič, D., \& Sriramesh, K. (2007). Defining strategic communication. International Journal of Strategic Communication, 1(1), 3-35. https://doi.org/10 $.1080 / 15531180701285244$

Hoye, R., Smith, A. C., Nicholson, M., \& Stewart, B. (2015). Sport management: Principles and applications. Routledge.

Jenny, S. E., Manning, R. D., Keiper, M. C., \& Olrich, T. W. (2017). Virtual(ly) athletes: Where eSports fit within the definition of "sport". Quest, 69(1), 1-18. https://doi.org/10.1080/00336297 .2016 .1144517

Keidell, R. (1987). Team sports models as a generic organisational framework. Human Relations, 40(9), 591-612. https://doi.org/10.1177/001872678704000904

Keller, K. (2013). Strategic brand management: Global edition. Pearson.

Kitchen, P. J. (1997). Was public relations a prelude to corporate communications? Corporate Communications: An International Journal, 2(1), 22-30. https://doi.org/10.1108/eb046531

McCarthy, J., Rowley, J., Ashworth, C. J., \& Pioch, E. (2014). Managing brand presence through social media: The case of UK football clubs. Internet Research, 24(2), 181-204. https://doi. org/10.1108/IntR-08-2012-0154

Nufer, G., Bühler, A., \& Jürgens, S. (2017). Brand identity management illustrated by Borussia Dortmund. In N. Chanavat, M. Desbordes, \& N. Lorgnier (Eds.), Routledge Handbook of Football Marketing (pp. 315-336). Routledge.

Parlebas, P. (1986). Éléments de sociologie du sport. PUF.

Pedersen, P. M. (2012). Media relations in sport. Journal of Policy Research in Tourism, Leisure and Events, 4(3), 383-385. https://doi.org/10.1080/19407963.2011.613232

Pedersen, P. M. (2013). Reflections on communication and sport: On strategic communication and management. Communication \& Sport, 1(1-2), 55-67. https://doi. org/10.1177/2167479512466655

Pedersen, P. M., Laucella, P. C., Miloch, K. S., \& Fielding, L. W. (2007). The juxtaposition of sport and communication: Defining the field of sport communication. International Journal of Sport Management and Marketing, 2(3), 193-207. https://doi.org/10.1504/IJSMM.2007.012400

Salgado. P., \& Ruão, T. (2013, June 5-7). FC Porto: A reputational perspective on corporate football [Paper presentation]. XVII International Conference on Corporate Reputation, Brand Identity and Competitiveness, Barcelona, Spain. http://hdl.handle.net/1822/29362

Smith, R. (2013). Strategic planning for public relations. Routledge. 
Smith, A., \& Stewart, B. (2014). Introduction to sport marketing. Routledge.

Spaaij, R., \& Westerbeek, H. (2010). Sport business and social capital: A contradiction in terms? Sport in Society, 13(9), 1356-1373. https://doi.org/10.1080/17430437.2010.510674

Stewart, B., \& Smith, A. (1999). The special features of sport. Annals of Leisure Research, 2(1), 87-99. https://doi.org/10.1080/11745398.1999.10600874

Taylor, J. R., \& Every, E.J. (2014). When organisation fails: Why authority matters. Routledge.

van Riel, C. B. (1995), Principles of corporate communications. Prentice Hall.

van Riel, C. B., \& Fombrun, C. J. (2007). Essentials of corporate communication: Implementing practices for effective reputation management. Routledge.

Weick, K. (1979). The social psychology of organising. McGraw-Hill.

Wenner, L. A. (2013). Reflections on communication and sport: On reading sport and narrative ethics. Communication \& Sport, 1(1-2), 188-199. https://doi.org/10.1177/2167479512467329

Winner, D. (2008). Brilliant orange: The neurotic genius of Dutch soccer. Abrams.

Wolfe, R. A., Weick, K. E., Usher, J. M., Terborg, J. R., Poppo, L., Murrell, A. J., Dukerich, J. M., Core, D., Dickson, K. E., \& Jourdan, J. S. (2005). Sport and organisational studies: Exploring synergy. Journal of Management Inquiry, 14(2), 182-210. https://doi.org/10.1177/1056492605275245 